\title{
Microsatellite Analysis and Urediniospore Dispersal Simulations Support the Movement of Puccinia graminis f. sp. tritici from Southern Africa to Australia
}

\author{
Botma Visser, ${ }^{\dagger}$ Marcel Meyer, Robert F. Park, Christopher A. Gilligan, Laura E. Burgin, \\ Matthew C. Hort, David P. Hodson, and Zacharias A. Pretorius
}

First and eighth authors: Department of Plant Sciences, University of the Free State, P.O. Box 339, Bloemfontein, 9300, South Africa; second and fourth authors: Epidemiology and Modelling Group, Department of Plant Sciences, University of Cambridge, Cambridge, CB2 3EA, UK; third author: Plant Breeding Institute Cobbitty, The University of Sydney, Private Mail Bag 11, Camden, NSW 2570, Australia; fifth and sixth authors: Atmospheric Dispersion and Air Quality (ADAQ), Met Office, Exeter, EX1 3PB, UK; and seventh author: International Maize and Wheat Improvement Center (CIMMYT), P.O. Box 5689, Addis Ababa, Ethiopia.

Accepted for publication 11 July 2018.

\begin{abstract}
The Australian wheat stem rust (Puccinia graminis f. sp. tritici) population was shaped by the introduction of four exotic incursions into the country. It was previously hypothesized that at least two of these (races 326$1,2,3,5,6$ and 194-1,2,3,5,6 first detected in 1969) had an African origin and moved across the Indian Ocean to Australia on high-altitude winds. We provide strong supportive evidence for this hypothesis by combining genetic analyses and complex atmospheric dispersion modeling. Genetic analysis of 29 Australian and South African P. graminis f. sp. tritici races using microsatellite markers confirmed the close genetic relationship between the

simulations using finely resolved meteorological data showed that long distance dispersal events between southern Africa and Australia are indeed possible, albeit rare. Simulated urediniospore transmission events were most frequent from central South Africa (viable spore transmission on approximately $7 \%$ of all simulated release days) compared with other potential source regions in southern Africa. The study acts as a warning of possible future $P$. graminis f. sp. tritici dispersal events from southern Africa to Australia, which could include members of the Ug99 race group, emphasizing the need for continued surveillance on both continents.
\end{abstract} South African and Australian populations, thereby confirming previously described phenotypic similarities. Lagrangian particle dispersion model
Additional keywords: exotic introduction, long-distance spore dispersal.
Many plant pathogens are transported on wind over long distances (Aylor 2003; Brown and Hovmøller 2002). The potential for long-distance dispersal (LDD) was first shown in pioneering studies conducted in the 1920s and 1930s using aircraft to collect spores at high altitudes. During a wheat rust epidemic in Manitoba in 1930, B. Peturson recorded the equivalent of approximately 16,000 trapped spores per square meter at an altitude of $\sim 4.5 \mathrm{~km}$ during repeated ascents (Gregory 1945). Recently, Weil et al. (2017) demonstrated the consequences of intercontinental LDD of microbes. Using a metagenomic approach, they showed that an extreme meteorological event in the form of a severe Saharan dust storm in 2014 deposited a large portion of an African microbial community on the Italian Dolomite Alps, thus confirming not only the reality of LDD, but also its effect on the recipient habitat.

The ability of rust fungi to produce vast numbers of spores that are resistant to UV irradiation, and temperature and relative humidity fluctuations, make them well adapted for LDD (Nagarajan and Singh 1990; Rotem et al. 1985; Viljanen-Rollinson and Cromey 2002). Three epidemiologically important spatial scales of LDD are distinguished in plant pathology, namely farm (from a single plant

†Corresponding author: B. Visser; E-mail: visserb@ufs.ac.za

Funding: The work was funded by the National Research Foundation of South Africa (grant number 87692) and the Australian Grains Research and Development Corporation. M. Meyer and C. A. Gilligan gratefully acknowledge financial support from the Bill and Melinda Gates Foundation, the BBSRC, and the Friedrich-EbertStiftung.

First and second authors contributed equally to this manuscript.

*The $\boldsymbol{e}$-Xtra logo stands for "electronic extra" and indicates that five supplementary files and three supplementary movies are published online.

(C) 2019 The American Phytopathological Society to within or across a field), regional (from a field over thousands of meters, even across county or state borders), and continental scales (between continents over thousands of kilometers) (Schmale and Ross 2015). Examples of regional LDD events of rusts include the annual wheat rust recolonization events of North America and Canada from Mexico (Kolmer 2001), the northern parts of China from the southern Ganzu, northern Sichuan, and Yunnan provinces (Chen et al. 2009) and the local movement within India (Tomar et al. 2014), western Europe, and northern Africa (Park et al. 2000) and Australia (Park et al. 1995). Putative continental scale dispersals include the trans-Atlantic movements of coffee leaf rust (Hemileia vastatrix) from Angola to Brazil in 1970 (Bowden et al. 1971), of sugarcane rust (Puccinia melanocefela) from Cameroon to America in 1978 (Purdy et al. 1985) and the introduction of soybean rust (Phakopsora pachyrhizi) into North America from South America through hurricane Ivan in 2004 (Schneider et al. 2005).

Despite its geographic isolation, Australia has experienced several exotic rust introductions in the past (Park et al. 2011). Melampsora medusae and M. larici-populina, the causal agents of poplar rust, were introduced into Australia in 1972 and 1973, respectively, probably due to infected plant material (Wilkinson and Spiers 1976). Human activity was the probable cause of the 1979 introduction of Puccinia striiformis f. sp. tritici to Australia (Wellings et al. 1987). The mode of introduction of the myrtle rust pathogen, Austropuccinia psidii, into Australia, is however unknown (Carnegie et al. 2010; Granados et al. 2017).

The detection of two wheat stem rust (Puccinia graminis Pers. f. sp. tritici Erikss.) races exotic to Australia in 1969, had a significant impact on $P$. graminis $\mathrm{f}$. sp. tritici diversity and occurrence in Australia over the following decades. At the time of first detection, standard races 326 and 194 were distinct from all previously characterized Australian P. graminis f. sp. tritici races (Watson and de Sousa 1982). Races 326-1,2,3,5,6 and 194-1,2,3,5,6, 
respectively, collected from wheat in South Australia and New South Wales (Zwer et al. 1992), were pathogenically very similar or closely related to $P$. graminis f. sp. tritici isolates collected in Angola and Zimbabwe (formerly Rhodesia) at the same time, suggesting that they have originated from Africa. Races 194 and 222 were previously recorded in Mozambique (Fonseca 1972; Watson and de Sousa 1982) and, together with race 326, in South Africa (Pretorius et al. 2007). Using isozyme profiles, Burdon et al. (1982) found no differences between selected African isolates and Australian races 326, 194 or their derivatives. Moreover, based on the isozyme profiles, it was suggested that race 21-0, first found in Australia in 1954 (Park 2007), may likewise have had an African origin (Burdon et al. 1982). Standard races 21, 326, and 194, all with a possible African origin, have subsequently been considered as the "founding ancestors" for P. graminis f. sp. tritici lineages 2, 3, and 4 in Australia (Park 2007).

While different means of transport could have caused the introduction of these races into Australia, wind dispersal was suggested as the most probable because the two 1969 races were collected at two locations 1,000 km apart (Watson and de Sousa 1982). At the end of the 1960s, human air travel frequencies and trade volumes between southern Africa and Australia were small. Thus, the probability of two separate human-mediated introductions happening in the same year to different locations in Australia seemed less likely than wind-mediated dispersal, where particularly conducive meteorological conditions in 1968/1969 could have led to the dispersal of the two races. Earlier documented $P$. graminis $\mathrm{f}$. sp. tritici incursions into Australia in 1925 and 1954 when even less air travel and trade occurred, further supported the hypothesis. Previous work also showed that constant level wind balloons released in Argentina and New Zealand circumvented the globe in only 10 to 12 days, passing over wheat areas in both southern Africa and Australia (Watson and de Sousa 1982).

Should the intercontinental dispersal of $P$. graminis f. sp. tritici urediniospores have occurred by means of high-altitude winds, then these rare, extremely long-distance events strongly shaped the Australian P. graminis f. sp.tritici population. This would suggest a risk for future exotic incursions that may affect wheat production in the country. This is especially important in the light of increased stem rust virulence in Africa, particularly the highly virulent Ug99 race group (Pretorius et al. 2000; Singh et al. 2015) and race TKTTF in Ethiopia (Olivera et al. 2015). It is thus important for future risk assessments to better understand the favorable circumstances, patterns and typical frequencies of long-distance high-altitude wind dispersal of rust urediniospores.

The aim of this study was to provide supporting evidence for historical LDD events involving movement of $P$. graminis $\mathrm{f}$. sp. tritici from southern Africa to Australia by (i) determining the genetic similarity between Australian and South African P. graminis f. sp. tritici races using microsatellite markers, and (ii) assessing the probability of LDD of $P$. graminis f. sp. tritici urediniospores using Lagrangian particle dispersion model (LPDM) simulations.

\section{MATERIALS AND METHODS}

Genotypic comparison of $\boldsymbol{P}$. graminis f. sp. tritici races. For microsatellite analysis, genomic DNA from 12 current South African and 16 Australian P. graminis f. sp. tritici races was used (Table 1). The Australian races represented the four lineages present in the country and included the original four introductions and several variants within each lineage. Ug99 race TTKSK, discovered in 1998 in Uganda and named in 1999 (Pretorius et al. 2000), was also included. The 17 microsatellite primers used (PgSUN3, PgSUN11, PgSUN14, PgSUN20, PgSUN22, PgSUN24, PgSUN25, PgSUN28, PgSUN29, PgSUN33, PgSUN35, PgSUN39, PgSUN40, PgSUN42, PgSUN44, PgSUN47, and PgSUN53) were described by Karaoglu et al. (2013). Each $10 \mu \mathrm{l}$ PCR reaction contained $5 \mathrm{ng}$ of genomic DNA, $1 \mu \mathrm{M}$ primers and a $1 \times$ dilution of KAPA Taq Ready Mix (KAPA Biosystems, Cape Town, South Africa). The amplification regime was $94^{\circ} \mathrm{C}$ for $5 \mathrm{~min}$, followed by 40 cycles of $94^{\circ} \mathrm{C}$ for $30 \mathrm{~s}$, specific annealing temperature for $30 \mathrm{~s}, 72^{\circ} \mathrm{C}$ for $30 \mathrm{~s}$ with a final extension step of $72^{\circ} \mathrm{C}$ for $5 \mathrm{~min}$. After confirming successful amplification on a $1.2 \%$ (wt/vol) agarose gel, the microsatellite amplicons were separated on a $5 \%$ (wt/vol) denaturing acrylamide gel using $1 \times$ TBE as running buffer (Sambrook et al. 1989) and the DNA fragments visualized with the Silver Sequence DNA Sequencing System (Promega, Madison, WI). A multilocus allelic data matrix based on the molecular sizes of the microsatellite markers was generated for all races. This was used to create an unrooted phylogram in DARwin 5.0.158 (Perrier et al. 2003) using the unweighted neighbor-joining (NJ) cluster analysis. A total of 30,000 bootstraps were included for the data set.

Genetic variability. The microsatellite markers were evaluated to determine if they could be used to effectively predict population structure among the South African and Australian P. graminis f. sp. tritici races. FSTAT 2.9.3.2 (Goudet 2001) was used to determine the within-population variation in terms of gene diversity, allelic richness, inbreeding coefficient $\left(\mathrm{F}_{\mathrm{IS} ;} 34,000\right.$ random permutations), and observed $\left(\mathrm{H}_{\mathrm{O}}\right)$ and expected $\left(\mathrm{H}_{\mathrm{E}}\right)$ heterozygosity. GENCLONE 2.0 (Arnaud-Haond and Belkhir 2007) was used to determine the genotypic diversity of the combined data set, as well as the number of multilocus genotypes (MLGs) under panmixia that was plotted against the number of loci used. MLGsim 2.0 (Stenberg et al. 2003) was used to confirm the clonality of MLGs that contained multiple copies by determining their psex and corresponding $P$ values. Linkage disequilibrium between different loci was tested using Arlequin 3.11 (Excoffier

TABLE 1. South African and Australian Puccinia graminis f. sp. tritici races included in the study ${ }^{\mathrm{a}}$

\begin{tabular}{|c|c|c|c|}
\hline Australian races & Australian lineage & South African races & South African lineage \\
\hline $126-5,6,7,11$ & AUS1 (1925) & 2SA4 & Non-Ug99 (1981) \\
\hline $21-0$ & AUS2 (1954) & 2SA55 & Non-Ug99 (2000) \\
\hline $326-1,2,3,5,6$ & AUS3 (1969) & 2SA88, TTKSF & Ug99 (2000) \\
\hline $194-1,2,3,5,6$ & AUS4 (1969) & 2SA88+, TTKSF+ & Ug99 (2010) \\
\hline $126-1,5,6,7,11$ & AUS1 (1973) & 2SA100 & Non-Ug99 (1984) \\
\hline $126-1,4,5,6,7,11$ & AUS1 (1966) & 2SA102 & Non-Ug99 (1988) \\
\hline $34-2$ & AUS2 (1999) & 2SA103 & Non-Ug99 (1988) \\
\hline $21-7$ & AUS2 (1968) & 2SA104 & Non-Ug99 (2003) \\
\hline $21-2,4,5$ & AUS2 (1967) & 2SA105 & Non-Ug99 (2005) \\
\hline $34-2,12,13$ & AUS2 (1984) & 2SA106, TTKSP & Ug99 (2007) \\
\hline $34-1,2,7+\operatorname{Sr} 38$ & AUS2 (2001) & 2SA107, PTKST & Ug99 (2009) \\
\hline $98-1,2,3,5,6,10$ & AUS3 (2000) & 2SA108 & Non-Ug99 (2010) \\
\hline $98-1,2,3,5,6,7$ & AUS3 (1979) & TTKSK & Ug99 (1998) \\
\hline $343-1,2,3,5,6$ & AUS3 (1974) & & \\
\hline 222-1,2,3,5,6+Einkorn & AUS3 (1982) & & \\
\hline $343-1,2,3,5,6,8,9+$ Norin40 & AUS3 (1982) & & \\
\hline
\end{tabular}

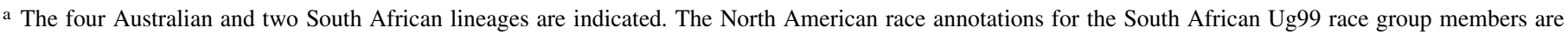
indicated in bold, while the date of first detection is indicated in brackets. 
et al. 2005) with 10,000 random permutations and a significance value of 0.05 .

Population structure analysis. The genetic similarity between the South African and Australian P. graminis f. sp. tritici races was further tested through clustering using discriminant analysis of principal components (DAPC), a nonparametric multivariate approach and the model-based Bayesian method implemented in STRUCTURE 2.23. The clone-corrected microsatellite dataset was used for both analyses. DAPC analysis (Jombart et al. 2010) was done with ADEGENET within the R environment where the number of clusters was based on the Bayesian information criterion (BIC). Genetic differentiation between the clusters was tested by determining the pairwise $F_{\mathrm{ST}}$ values between clusters with the Arlequin 3.11 software package (Excoffier et al. 2005). Significance was tested using 3,000 random permutations.

The resulting number of clusters was confirmed using the Bayesian model-based clustering option within STRUCTURE 2.23 (Pritchard et al. 2000). The $K$ values ranged from 1 to 10 with a total of 10 repetitions included for each $K$ value, with both burn-in period length and Monte Carlo Markov Chain (MCMC) iterations set at 10,000 . The optimal number of clusters was calculated using the Admixture model with the ad hoc $\Delta K$ statistic (Evanno et al. 2005) as implemented in CLUMPAK (Kopelman et al. 2015). CLUMPAK was also used to create the optimal cluster alignment across different $K$ values. Once the actual $K$ value was confirmed, the run was repeated with a 100,000 burn-in period length and 100,000 MCMC iterations.

Based on the DAPC and STRUCTURE results, the genetic variation between clusters, groups within the clusters and races within groups was determined using analysis of molecular variance (AMOVA) (Excoffier et al. 1992) within Arlequin 3.11 (Excoffier et al. 2005). After setting the significance level at 0.05 and the number of permutations to 16,000 , the fixation index $\left(F_{\mathrm{ST}}\right)$ was calculated. An $F_{\mathrm{ST}}$ value greater than 0.25 indicated significant genetic differentiation between subpopulations (Hartl and Clark 1997).

$P$. graminis f. sp. tritici urediniospore dispersal simulations. To assess the probability of LDD of $P$. graminis f. sp. tritici urediniospores from southern Africa to Australia, LPDM simulations were conducted using the UK Met Office's Lagrangian particle dispersion model, NAME (Jones 2013; Jones et al. 2007), with a previously tested parameterization for $P$. graminis f. sp. tritici urediniospore dispersal (Meyer et al. 2017a, b; Olivera et al. 2015). The global analysis data of the UK Met Office's Unified Model was used as meteorological input (Davies et al. 2005). The data contained a set of three-dimensional, spatio-temporally varying meteorological fields including mean wind speed, pressure and precipitation. The meteorological data have a three-hourly temporal resolution and spatial resolution ranging from $\sim 60 \mathrm{~km}$ horizontally (with 31 vertical layers) in 2003 to $\sim 17 \mathrm{~km}$ horizontally (with 59 vertical layers) in 2016.

P. graminis f. sp. tritici urediniospore release was simulated from 0900 to 1500 local time for 14 years from 2003 to 2016 during August to November from five source-locations in southern Africa, namely southern Tanzania $\left(-9.21^{\circ} \mathrm{S}, 34.34^{\circ} \mathrm{E}\right)$, Zambia $\left(-15.87^{\circ} \mathrm{S}\right.$, $\left.27.9^{\circ} \mathrm{E}\right)$, Zimbabwe $\left(-19.93^{\circ} \mathrm{S}, 32.33^{\circ} \mathrm{E}\right)$, and central $\left(-28.1^{\circ} \mathrm{S}\right.$, $\left.27.71^{\circ} \mathrm{E}\right)$ and southern South Africa $\left(-34.23^{\circ} \mathrm{S}, 20.01^{\circ} \mathrm{E}\right)$. The source-locations were chosen to represent key wheat producing regions in these countries and suitable stem rust environments based on field survey data. The release time was restricted to August to November in which the seasonal timing of the main wheat production areas in both continents overlaps, i.e., susceptible wheat fields are present in source and target countries and thus allow for LDD from infected to susceptible hosts.

In the absence of field data on urediniospore canopy escape rates, the source-strength of all sources was set to simulate a constant daily unit emission (1 spore mass per day per source) with analysis of resulting relative proportions of released to deposited urediniospore deposition per day, as well as the number of days with any nonzero urediniospore deposition on wheat areas in Australia. A total of $10^{6}$ simulation particles per day per source was used for a robust treatment of turbulent transport processes. We accounted for loss of viability of spores during atmospheric transport by modeling exponential decay of urediniospore viability over a 3-day urediniospore lifetime, with the decay rate defined to approximate available experimental results of the survival of urediniospores exposed to UV radiation (Maddison and Manners 1972). An additional set of simulations was run for a longer 5-day urediniospore lifetime to test the sensitivity and robustness of the simulation inferences to the maximum lifetime of urediniospores, a key model parameter. This was done because published experimental results (Maddison and Manners 1972) do not preclude the possibility that a very small proportion $(<1 \%)$ of spores may survive longer than 3 days.

Our core parameterization with a 3-day lifetime accounts for the majority of spores and was chosen in an attempt not to overestimate transmission risks. The deposition of spore material from the threedimensional position of each simulation particle by sedimentation, and dry and wet deposition was simulated as a function of input meteorology, topography, and biophysical characteristics of $P$. graminis f. sp. tritici urediniospores (density $\rho=1 \mathrm{~g} / \mathrm{cm}^{3}$ [Orr and Trippets 1972] with the diameter of spherical particles $d=26.4 \mu \mathrm{m}$ [Eversmeyer and Kramer 2000] and default scavenging coefficients for small particulates in the size range of urediniospores [Jones 2013]). Total daily urediniospore deposition amounts were obtained for each grid-cell of a two-dimensional grid with an approximate resolution of $10 \mathrm{~km}\left(0.083^{\circ}\right)$ covering southern African countries, the southern Indian Ocean and Australia (spatial domain: -20 to $-70^{\circ} \mathrm{S}, 10$ to $160^{\circ} \mathrm{E}$ ). Deposition grids were analyzed to determine urediniospore deposition on wheat producing areas in Australia (You et al. 2005). Three regions of deposition were distinguished: (i) West Australia (longitudes $<126^{\circ} \mathrm{E}$ ), (ii) East Australia (longitudes $>126^{\circ} \mathrm{E}$ ), and (iii) Australia as a whole.

The simulation analysis was conducted for all days within the specified months of the 14-year study period. The total number of days with nonzero urediniospore deposition was counted to obtain long-term trends of potential urediniospore transmission frequencies (number of deposition events per release time period) to different parts of Australia where the exotic P. graminis f. sp. tritici races were detected.

For the source location with highest transmission frequencies (central South Africa), additional simulations were conducted for one exemplar year (2016) to analyze in more detail the different types of deposition (wet and dry) on Australian wheat areas, as well as the effect of altitude, cloud cover, humidity, and UV radiation on deposition amounts. Wet and dry deposition amounts were sampled separately, and the deposition amounts compared using two different model variants. The first was the above-mentioned model where the time-dependent exponential decay of spore viability was used. The second model variant (Meyer et al. 2017a) includes a UV dosedependent decay of spore viability, which accounts for altitude, cloud cover and relative humidity at the position of each simulation particle to approximate the viability decay of urediniospores.

The long study period, finely resolved global meteorological data ( $\sim 9$ TB input data) and large number of simulation particles required high-performance computing resources. Simulations were conducted on the computing cluster of the Epidemiology and Modeling Group in Cambridge, consisting of 20 machines (Intel Xeon E5-2650; each with 128 GB RAM, 16 cores, 20 MB SmartCache, 2 GHz Processor Base Frequency and $\approx 7 \mathrm{~TB}$ disk space).

\section{RESULTS}

Genotypic comparison of $\boldsymbol{P}$. graminis $\mathrm{f}$. sp. tritici races. The unweighted NJ phylogram for all $P$. graminis f. sp. tritici races tested revealed three distinct groups (Fig. 1). The first contained the original Australian race 126-5,6,7,11 and its two variants, which 
shared a maximum of $29.5 \%$ genetic similarity with the rest of the tested races. All the South African members of the Ug99 race group, including TTKSK, formed group two with a maximum of $32.4 \%$ genetic similarity with the rest. The final group included all the South African non-Ug99 races and the Australian races from lineages 2, 3, and 4, which was further divided into three smaller subgroups.

The largest of these contained a mixture of South African and Australian races. Australian $P$. graminis $\mathrm{f}$. sp. tritici introduction 326-1,2,3,5,6 representing lineage 3 grouped with South African races 2 SA 4, 2SA100, and 2SA105 sharing 94.2\% genetic similarity, while Australian introduction 194-1,2,3,5,6 representing lineage 4 shared 91.1 and $85.3 \%$ genetic similarity with 2SA55 and 2SA102 respectively. Several variants within Australian lineages 3 and 4 also formed part of this subgroup. Australian introduction 210 representing lineage 2 formed part of the second largest subgroup consisting of only Australian races. Race 21-0 shared the highest genetic similarity (79.4\%) with South African races 2SA100, 2SA103, and 2SA104. The two latter races, together with 2SA108, formed the smallest subgroup consisting of only South African races.

Observed genetic variation. Genetic variation was calculated for two P. graminis f. sp. tritici groups containing the Australian and South African races, respectively (Supplementary File S1). While the average number of alleles per locus was very similar, the South African races exhibited higher genetic diversity and allelic richness that could imply a possible founder effect created by the introductions in Australia. The combined data set had a genotypic diversity of 0.821 . This high value was most probably due to the distinctive genotypes for Australian race 126 and its derivatives and the four South African members of the $\mathrm{Ug} 99$ race group and TTKSK when compared with the rest of the Australian and South African races.

The alternate host for $P$. graminis f. sp. tritici, Berberis, is not native to either country. The sexual stage of the life cycle is thus either absent or very rare. Clonal reproduction of $P$. graminis $\mathrm{f}$. sp.

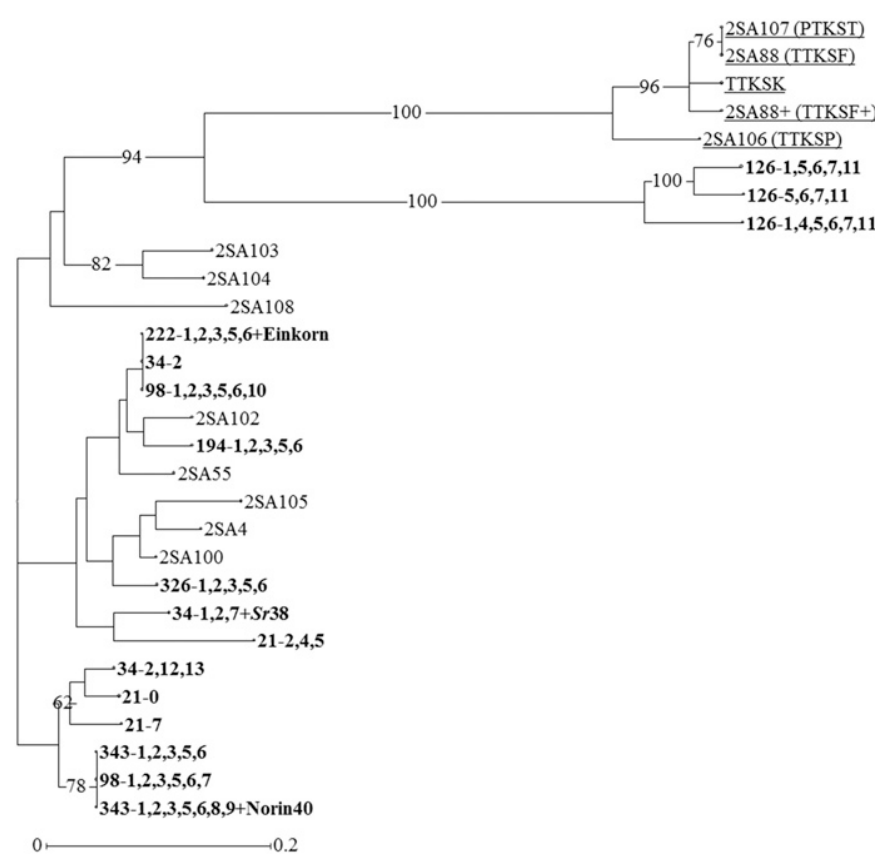

Fig. 1. Genetic comparison of 29 South African and Australian Puccinia graminis $\mathrm{f}$. sp. tritici races using an unrooted neighbor-joining tree based on allelic data for 17 microsatellite markers (Karaoglu et al. 2013). Bootstrap values greater than 60 are indicated on the connecting lines. The Australian races are indicated in bold, the four South African Ug99 race group members, including TTKSK, are underlined and the South African non-Ug99 races are given in normal script. The North American race annotations for the $\mathrm{Ug} 99$ race group are indicated in brackets. tritici in the two countries was supported by the microsatellite data. When all the races were combined into one population, the observed heterozygosity was lower than what was expected. This was confirmed, with the two individual populations both exhibiting significant positive inbreeding coefficients. Finally, the psex values for all MLGs having multiple individuals also supported the clonality of the populations with statistical significance (results not shown).

The 29 P. graminis $\mathrm{f}$. sp. tritici races were divided into 24 MLGs with races 2SA88 and 2SA107, races 34-2, 222-1,2,3,5,6+Einkorn and $98-1,2,3,5,6,10$, and races $98-1,2,3,5,6,7,343-1,2,3,5,6$, and 343-1,2,3,5,6,8,9+Norin40 being clonal (Fig. 1). When the 24 MLGs were plotted against the 17 microsatellite loci (Supplementary File S2), the number of loci was sufficient to distinguish all MLGs. Because five markers (PgSUN3, PgSUN20, PgSUN22, PgSUN25, and PgSUN53) showed evidence of linkage with other markers, each was individually omitted from the data set and clustering retested. In a final test, all five markers were simultaneously omitted from the data set. In all cases, no change in the clustering pattern was observed and all primer sets were subsequently included in the final data set.

Clustering of races. The grouping of races in the phylogram was supported by both DAPC and STRUCTURE analyses. With $K=$ 4 as indicated by the BIC curve, four distinct clusters were evident on the DAPC scatterplot with the Ug99 and 126 clusters grouping separate from each other, as well as from the other two (Fig. 2). Clusters 2 and 3, each containing a mixture of South African nonUg99 and Australian genotypes, overlapped with each other, indicating close genetic similarity between the genotypes. This was confirmed with the pairwise $F_{\mathrm{ST}}$ comparison (Table 2 ). The highest genetic differentiation as indicated by the high $F_{\mathrm{ST}}$ values were among clusters 126, Ug99 and the combined clusters 2 and 3, while the lowest was between clusters 2 and 3 .

Model-based clustering of genotypes with STRUCTURE also recognized $K=4$ as optimal (Supplementary File S3). The clustering of genotypes with increasing $K$-values is indicated in

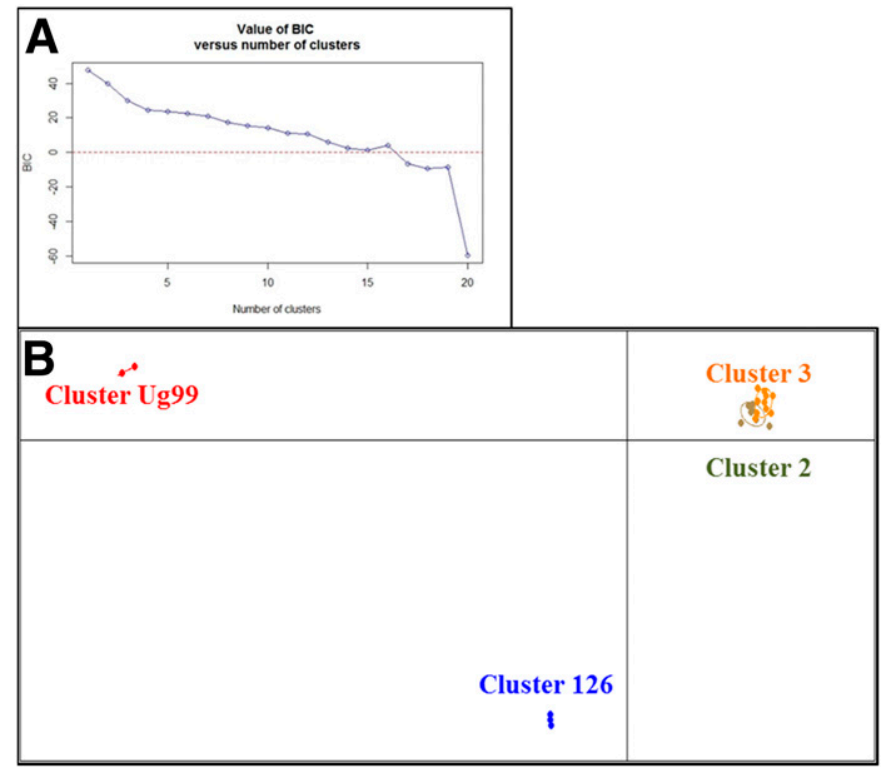

Fig. 2. Assignment of 24 South African and Australian Puccinia graminis f. sp. tritici multilocus genotypes into four genetic clusters based on discriminant analysis of principal components using the clone-corrected microsatellite dataset. A, The $K=4$ clusters were supported by the clear "elbow" seen in the Bayesian information criteria (BIC) graph. B, Scatterplot of the four $P$. graminis f. sp. tritici clusters. Cluster Ug99 contained all four South African members of the Ug99 race group and TTKSK, while the three Australian race 126 variants formed cluster 126. Clusters 2 and 3 comprised of a mixture of South African non-Ug99 races and Australian lineage 2, 3, and 4 races. The first two components of the eigenvalues described $87.5 \%$ of the genetic structure of the analysis. 
Supplementary File S4. At $K=2$, the $\mathrm{Ug} 99$ and race 126 genotypes were clustered together but separate from the rest, but were themselves separated at $K=3$. At $K=4$, the South African nonUg99 and Australian lineage 2, 3, and 4 genotypes split into two mixed clusters (Fig. 3). Besides the admixture event of race 2SA108 at $K=5$, no further significant differentiation was detected. The four clusters were highly differentiated with very little admixture (Fig. 3) as was confirmed with an $F_{\text {ST }}$ value of $0.78(P<0.0001)$ as determined with AMOVA. Most $(71.3 \%)$ of the genetic variation was accounted for by variation between the four clusters, with less variation occurring between groups within the clusters $(6.4 \%)$ and between races within groups $(22.3 \%)$ within the clusters.

LDD simulations. The LPDM simulations confirmed that the extremely long-distance $(8,000$ to $12,000 \mathrm{~km})$ dispersal of $P$. graminis f. sp. tritici urediniospores from southern Africa to Australia is possible, albeit rare (Table 3; Figs. 4 and 5). Visual inspection of the daily simulated deposition plumes showed that deposition patterns emanating from the five source-locations differed markedly in terms of the predominant direction of spread, spatial dilution and anisotropy of spore clouds (Fig. 4).

The number of days with any nonzero deposition over 14 years was counted to estimate the mean proportion of release days on which spore transport to Australia is possible (Table 3). In simulations using a maximum urediniospore lifetime of 3 days, the proportion of release days with viable spore deposition in

TABLE 2. Genetic differentiation between four Puccinia graminis f. sp. tritici clusters calculated with discriminant analysis of principal components ${ }^{\mathrm{a}}$

\begin{tabular}{lcccc}
\hline Cluster & Cluster 126 & Cluster 2 & Cluster 3 & Cluster Ug99 \\
\hline Cluster 126 & - & 0.768 & 0.801 & 0.865 \\
Cluster 2 & 0.009 & - & 0.369 & 0.808 \\
Cluster 3 & 0.002 & 0.000 & - & 0.832 \\
Cluster Ug99 & 0.023 & 0.004 & 0.001 & - \\
\hline
\end{tabular}

a Pairwise $F_{\mathrm{ST}}$ values are indicated in the upper and their significance values $(<0.05)$ in the lower diagonal. The analysis was based on 17 microsatellite markers.
Australia varied between 0 and $7.5 \%$. The transmission was highest from central South Africa, resulting in viable urediniospore transport to West Australia on $6.4 \%$ of release days and East Australia on $2 \%$ of release days. These simulated transmission frequencies from central South Africa were approximately three times higher than those from the southern South African source and five to six times higher than from Zimbabwe. Extremely low transmission frequencies were found for Zambia and no transmission from Tanzania, the southernmost country of the East African Rift Valley epidemiological zone. From the central South African source, there was at least one day in each year with meteorological conditions conducive for long-distance transport. However, notable monthly and annual variation were evident (Fig. 5). The potential for transmission from central South Africa was the highest in September (Table 3; Fig. 5B).

Two different urediniospore transmission scenarios to Australia were evident. In the first that occurred most of the time, urediniospore plumes pass over Australia from the west extending all the way to the east with viable urediniospore deposition on wheat areas across several Australian states. Alternatively, the urediniospore cloud misses West Australia entirely but crosses the coast in the southeast of Australia with spore deposition only on the southern/southeastern wheat areas.

The vertical distribution of airborne spore transport altitudes in simulations varied strongly in space (at different latitudinal and longitudinal positions) and time, depending on the meteorological conditions. For example, the mean urediniospore plume height from central South Africa for the release day shown in Figure 4D increased from the surface up to $\sim 5 \mathrm{~km}$ altitude within the first $24 \mathrm{~h}$ of dispersal. It then reached a peak of $\sim 7 \mathrm{~km}$ above ground on day two before descending to $\sim 5 \mathrm{~km}$ after $48 \mathrm{~h}$ and less than $2 \mathrm{~km}$ after $72 \mathrm{~h}$. After the initial release period, the mean vertical plume spread varied between $\sim 0.5$ to $2.5 \mathrm{~km}$.

Deposition amounts of simulated spores on Australian wheat areas varied greatly from day to day, from zero on most days to nonzero deposition amounts ranging over more than 10 orders of magnitude as calculated for 2016 (Fig. 5A). With no canopy escape rate data available for the source area, simulations were conducted using a unit emission of one spore material per day per source. This

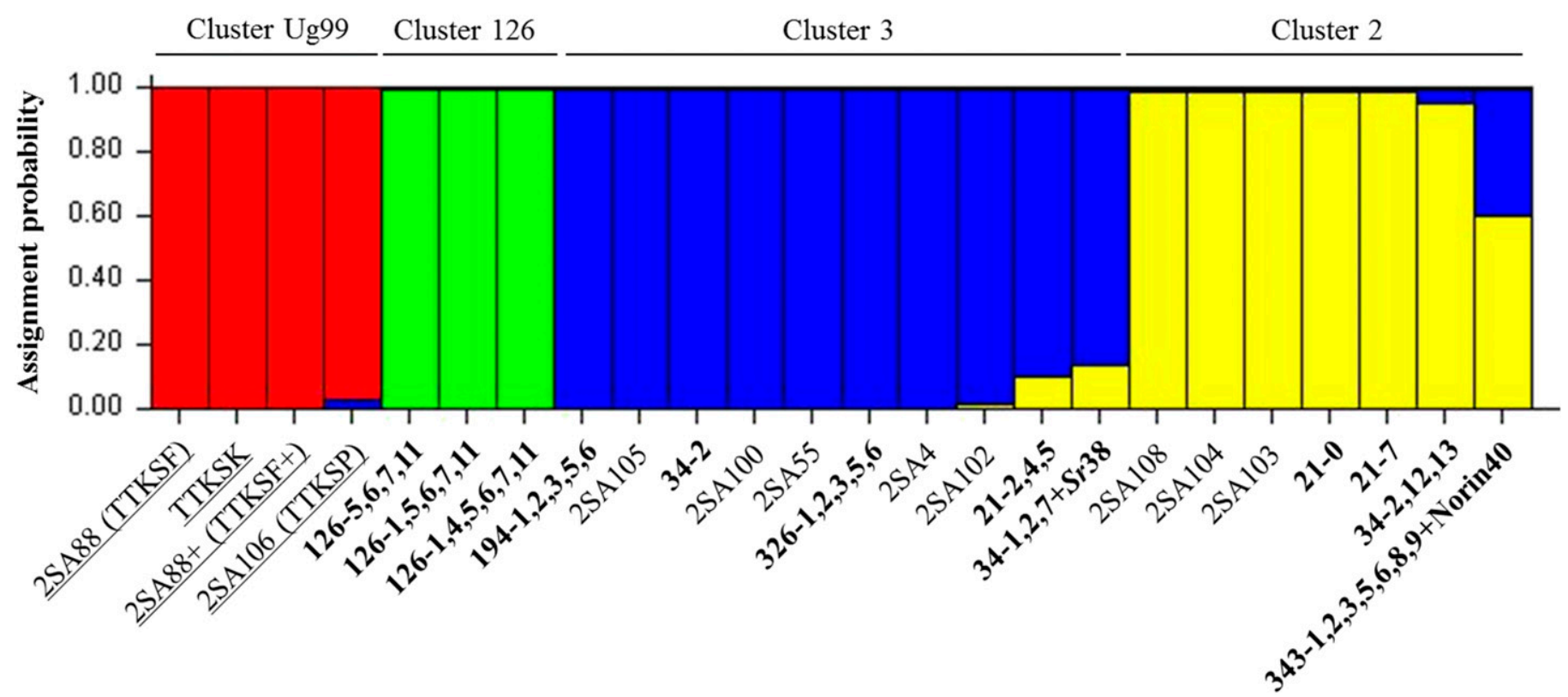

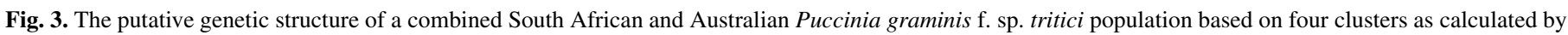

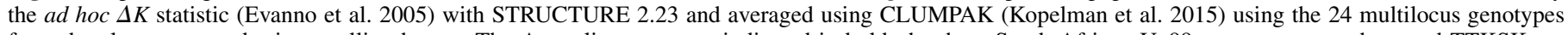

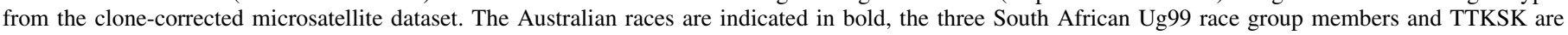

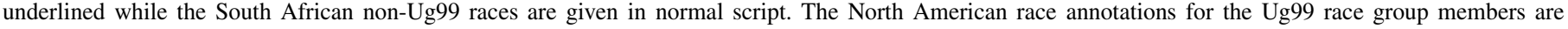
indicated in brackets. 
means that the recorded proportion of released to deposited spores in Figure 5A may be interpreted as single spore transmission probabilities. In real life, $\sim 10^{11}$ to $10^{12}$ urediniospores are produced per hectare per day. In case of a localized epidemic, where hundreds to thousands of hectares are infected, the aggregate total daily spore canopy escape rate will be in the order of $\sim 10^{12}$ to $10^{15}$ urediniospores per day (Meyer et al. 2017b). A small proportion of this released spore cloud may reach the distant targets.

The majority of simulated deposition events in Australia in 2016 from the source in central South Africa were wet deposition events when a maximum spore lifetime of 3 days was used. When the spore lifetime was increased to 5 days (Supplementary File S5), the contribution of dry and wet deposition to the total deposition amount varied considerably. This indicated that successful transmission of spores with a shorter lifetime is only possible if the final step of the atmospheric transport process involves a quick rainout from higher altitudes. In the case of a longer spore lifetime, spores are deposited not only via rainout, but also by transport of airmasses to the ground.

Because environmental drivers such as UV radiation could affect spore viability, total spore deposition in West and East Australia was calculated for 2016 from the source in central South Africa using two model variants, namely time-dependent exponential decay and UV dose-dependent decay of spore viability (Fig. 5A). Three key observations were made: first, there was a notable effect (1 to 3 orders of magnitude) of the viability function on deposition amounts. This was however still much smaller (about 10 orders of magnitude) than the total range of deposition amounts observed. Secondly, deposition amounts obtained for UV dose-dependent decay simulations fluctuated around those of the time-dependent exponential decay simulations. This was because the meteorological variables (cloud cover, relative humidity, and altitude) that drive the UV dose-dependent decay experienced by each simulation particle in different parts of spore clouds, fluctuated strongly. Finally, the time-dependent exponential decay model overestimated spore viability, compared with the UV dose-dependent scheme, for the extremely long-distance transmission events to East Australia, because the majority of these spore clouds must be transported at very high altitudes with increased UV radiation exposure.

It is important to note that the obtained long-term transmission frequencies (Table 3 ) are independent of the shape of the viability decay function (time-dependent versus UV dose-dependent), as long as it is assumed that a small proportion of released spores remain viable until the maximum 3-day lifetime has passed. This is because all days with any nonzero deposition amount on wheat areas in Australia were counted. However, increasing the maximum urediniospore lifetime from 3 to 5 days led to a marked increase in urediniospore transmission frequencies from all sources (Fig. 5B and C).

\section{DISCUSSION}

The term "global village" was coined to describe the interconnectedness of different regions of the world. This implies that events affecting one region could in theory quickly spread to distant regions. This is especially true of microbial pathogens causing human and plant diseases (Brown and Hovmøller 2002). Increased travel and trade will in future only exacerbate this phenomenon. While many countries implement strict quarantine conditions at all points of entry to prevent the accidental introduction of microbial pathogens, this strategy does not protect against windmediated LDD events.

The periodic discovery of new wheat rust races in Australia highlights the country's vulnerability to foreign introductions, despite its relative geographic isolation. The appearance of four novel $P$. graminis f. sp. tritici races between 1925 and 1969 clearly influenced the stem rust population within Australia (Park 2007). These introductions respectively formed the basis of four different P. graminis f. sp. tritici lineages that dominated from 1925 to 1954 (race 126), 1955 to the early 1980s (race 21-0) and 1969 until the present (races 326 and 194). Multiple clonal variants subsequently arose within all four linages with, for instance, races 343 and 98 and their respective variants developing from race 326 . Two of the introductions, 326-1,2,3,5,6 and 194-1,2,3,5,6, were suggested to have originated from Africa (Watson and de Sousa 1982), while the origin of 21-0 was speculated either to be Africa (Luig 1977) or Tasmania (Watson 1958). The origin of 126-5,6,7,11 was unknown.

The current study clearly supports earlier isozyme results (Burdon et al. 1982) of an African origin for 326-1,2,3,5,6 and 194-1,2,3,5,6. Both races shared $85 \%$ genetic similarity with several of the current South African races. Both DAPC and STRUCTURE analysis grouped these two races, together with race

TABLE 3. Long-term atmospheric Puccinia graminis f. sp. tritici urediniospore transmission frequencies calculated in Lagrangian particle dispersion model simulations using NAME with a maximum 3-day urediniospore lifetime ${ }^{a}$

\begin{tabular}{|c|c|c|c|c|c|}
\hline Location & August (2003-2016) & September (2003-2016) & October (2003-2016) & November (2003-2016) & All months (2003-2016) \\
\hline \multicolumn{6}{|l|}{ Southern Tanzania } \\
\hline West Australia & $\bar{P}=0 / 434=0.000$ & $\bar{P}=0 / 420=0.000$ & $\bar{P}=0 / 434=0.000$ & $\bar{P}=0 / 420=0.000$ & $\bar{P}=0 / 1708=0.0000$ \\
\hline East Australia & $\bar{P}=0 / 434=0.000$ & $\bar{P}=0 / 420=0.000$ & $\bar{P}=0 / 434=0.000$ & $\bar{P}=0 / 420=0.000$ & $\bar{P}=0 / 1708=0.0000$ \\
\hline \multicolumn{6}{|l|}{ Zambia } \\
\hline West Australia & $\bar{P}=0 / 434=0.000$ & $\bar{P}=0 / 420=0.000$ & $\bar{P}=0 / 434=0.000$ & $\bar{P}=1 / 420=0.002$ & $\bar{P}=1 / 1708=0.0006$ \\
\hline East Australia & $\bar{P}=0 / 434=0.000$ & $\bar{P}=0 / 420=0.000$ & $\bar{P}=0 / 434=0.000$ & $\bar{P}=0 / 420=0.000$ & $\bar{P}=0 / 1708=0.0000$ \\
\hline Australia & $\bar{P}=0 / 434=0.000$ & $\bar{P}=0 / 420=0.000$ & $\bar{P}=0 / 434=0.000$ & $\bar{P}=1 / 420=0.002$ & $\bar{P}=1 / 1708=0.0006$ \\
\hline East Australia & $\bar{P}=0 / 434=0.000$ & $\bar{P}=0 / 420=0.000$ & $\bar{P}=6 / 434=0.014$ & $\bar{P}=0 / 420=0.000$ & $\bar{P}=6 / 1708=0.0035$ \\
\hline Australia & $\bar{P}=1 / 434=0.002$ & $\bar{P}=6 / 420=0.014$ & $\bar{P}=10 / 434=0.023$ & $\bar{P}=10 / 420=0.024$ & $\bar{P}=27 / 1708=0.0158$ \\
\hline \multicolumn{6}{|c|}{ Central South Africa } \\
\hline West Australia & $\bar{P}=15 / 434=0.035$ & $\bar{P}=46 / 420=0.110$ & $\bar{P}=17 / 434=0.039$ & $\bar{P}=32 / 420=0.076$ & $\bar{P}=110 / 1708=0.0644$ \\
\hline East Australia & $\bar{P}=2 / 434=0.005$ & $\bar{P}=13 / 420=0.031$ & $\bar{P}=11 / 434=0.025$ & $\bar{P}=9 / 420=0.021$ & $\bar{P}=35 / 1708=0.0205$ \\
\hline Australia & $\bar{P}=17 / 434=0.039$ & $\bar{P}=52 / 420=0.124$ & $\bar{P}=23 / 434=0.053$ & $\bar{P}=37 / 420=0.088$ & $\bar{P}=129 / 1708=0.0755$ \\
\hline
\end{tabular}

${ }^{a}$ Indicated are transmission frequencies from five different source-locations in Africa to both Western and Eastern Australia, respectively, and Australia as a whole. Transmission frequencies are denoted as $\bar{P}=N_{\text {dep }} / N_{\text {rel }}$, where $N_{\text {dep }}$ is the number of viable urediniospore deposition days per time period and $N_{\text {rel }}$ is the total number of release days per time period. 
326 variant 98-1,2,3,5,6,10 and five South African races, into one of the four proposed clusters. Three other race 326 variants $(98-$ $1,2,3,5,6,7,343-1,2,3,5,6$, and 343-1,2,3,5,6,8,9+Norin40) grouped within the second cluster with three other South African races. This clearly indicated a close genetic relationship between these South African and Australian races.
This study also confirmed that the origin of race $21-0$ most probably was Africa (Luig 1977). It shared at least $80 \%$ genetic similarity with three South African races, thereby supporting an African origin as was previously suggested (Burdon et al. 1982). In contrast, the distinct genetic profile of 126-5,6,7,11 could not support an African origin and its origin remains unknown. The

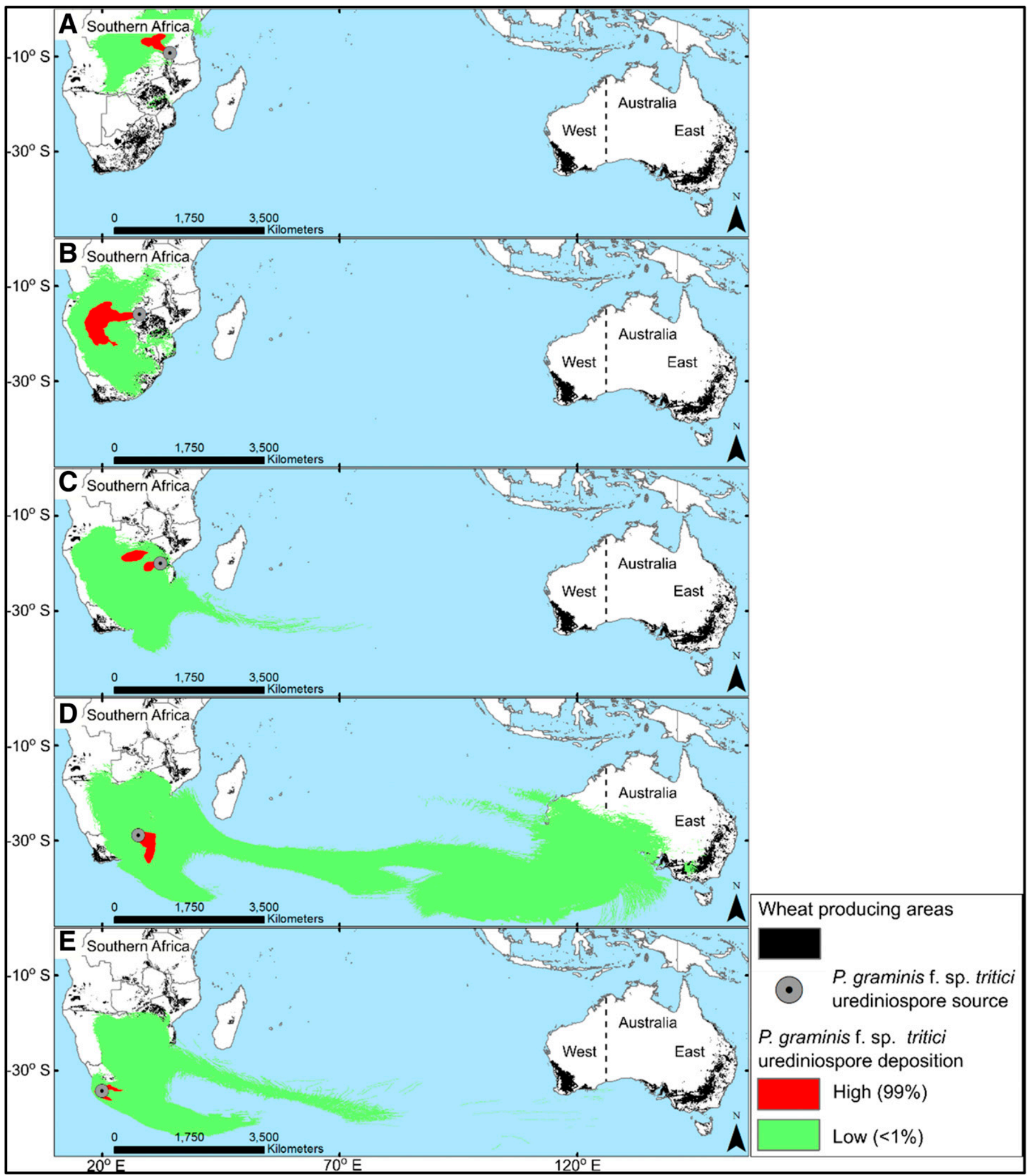

Fig. 4. Simulated atmospheric long-distance dispersal and deposition of Puccinia graminis f. sp. tritici urediniospores with a maximum 3-day lifetime, from southern Africa to Australia. Indicated are total daily deposition plumes for one exemplar day (23 September 2013) during the 14-year study period resulting from urediniospore release from A, south Tanzania, B, Zambia, C, Zimbabwe, D, central South Africa, and E, south South Africa. Relative proportions of total spore deposition are illustrated. 
placement of Australian races 21-0 and 126 in terms of the South African races was supported by Lewis et al. (2018) using genome sequence data.

Watson and de Sousa (1982) suggested that the P. graminis f. sp. tritici urediniospores were transported by high-altitude wind across the Indian Ocean. This hypothesis was supported by the LPDM simulations done in this study that strongly indicated that, on rare occasions, airborne urediniospore transport from sources in southern Africa over the Indian Ocean to wheat areas in both Western and eastern Australia, is possible.

We used advanced computational methods to assess if the intercontinental airborne LDD of $P$. graminis $\mathrm{f}$. sp. tritici urediniospores is

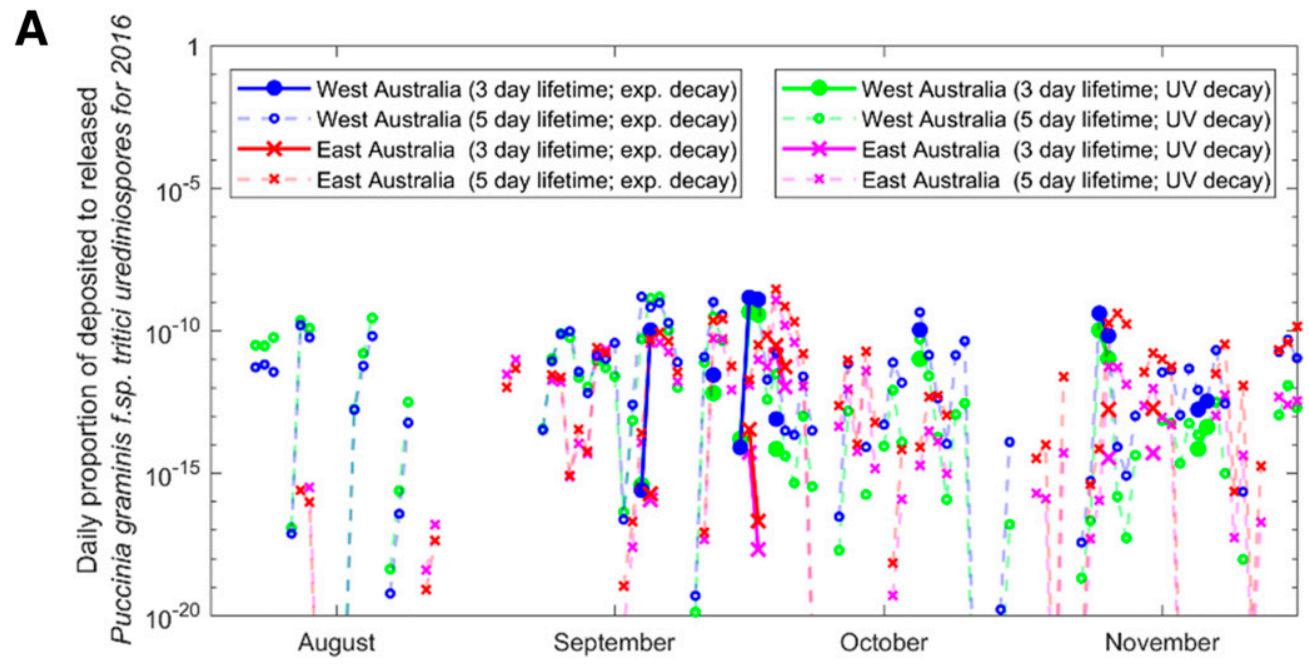

B

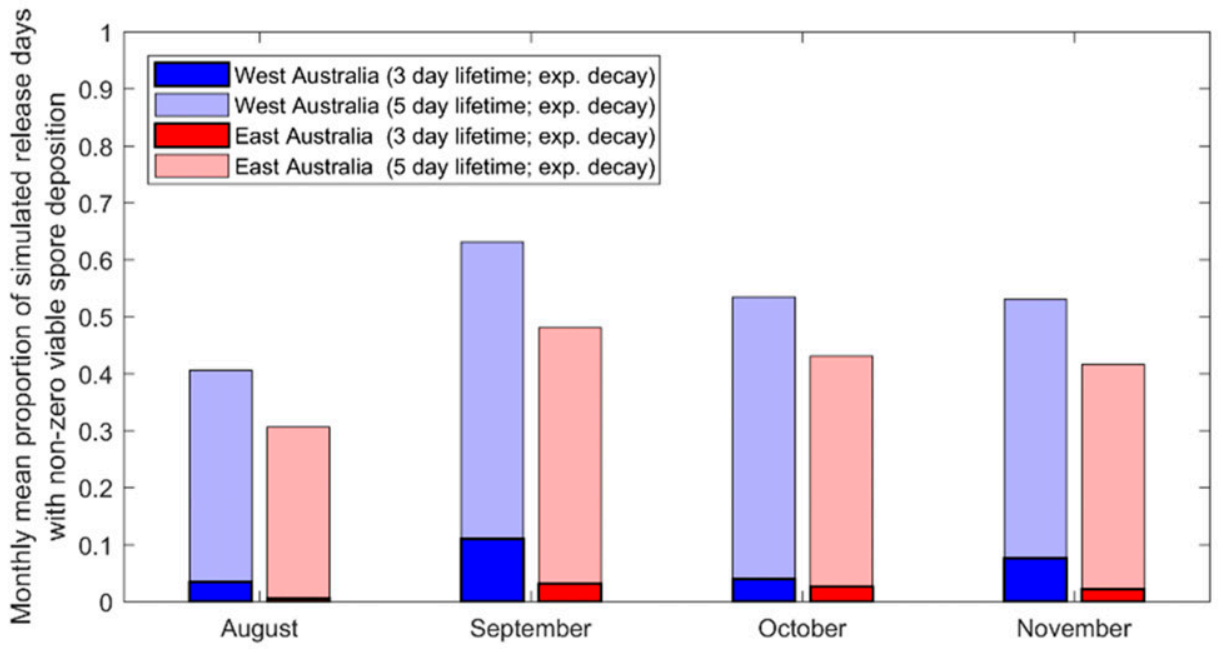

C

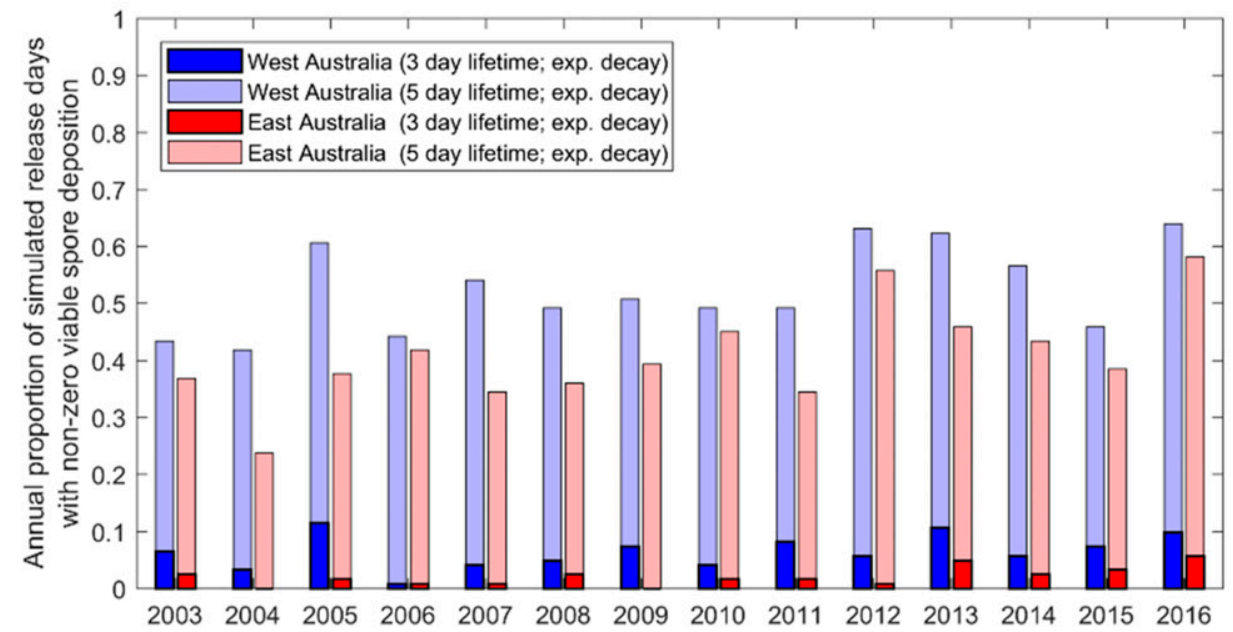

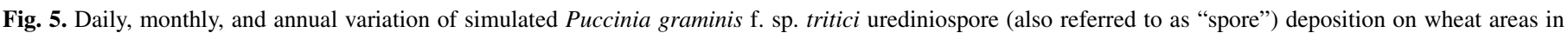

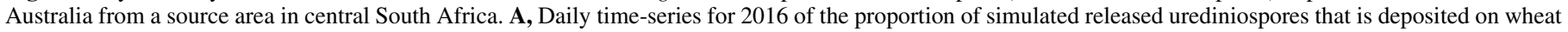

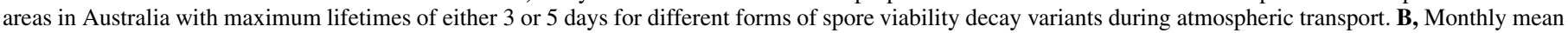

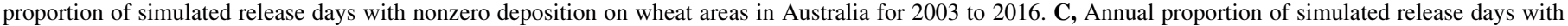
nonzero deposition on wheat areas in Australia for 2003 to 2016. 
possible by tracing hundreds of millions of stochastic trajectories over more than a decade to obtain a quantitative estimate of typical frequencies of such events. It is possible with current modeling techniques, finely resolved meteorological data and high-performance computing power to obtain probabilistic approximations of longterm mean transport quantities of a spore cloud in atmospheric flows (Meyer et al. 2017a; Meyer et al. 2017b). The accuracy of these predictions depends inter alia on, for example, case-specific atmospheric flow regimes, the specific type of dispersal model used and the quality of meteorological input data.

Previous studies of plant pathogen dispersal used constant pressure trajectories and balloons (Nagarajan et al. 1976; Watson and de Sousa 1982), analysis of predominant wind fields (Bowden et al. 1971; Singh et al. 2006), mean trajectory models (Sadyś et al. 2014; Singh et al. 2011), Gaussian plume or puff models (Aylor 2003; Gregory 1945; Prussin et al. 2015), Lagrangian stochastic simulations on field scales (Aylor et al. 2011), the integrated aerobiological modeling system (IAMS) (Isard et al. 2005), as well as HYSPLIT (Kim and Beresford 2008; Pan et al. 2006; Wang et al. 2010) and NAME (Meyer et al. 2017a; Meyer et al. 2017b; Olivera et al. 2015). The latter two are complex atmospheric dispersal modeling environments that allow the user to choose different types of LDD modeling for different temporal and spatial scales.

In the current study, the LPDM, NAME (Jones 2013; Jones et al. 2007), was used to simulate spore dispersal. The model was originally developed by the UK Met Office for radionuclides, but was subsequently adapted for volcanic ash, fires, and more recently, insect vectors (Burgin et al. 2013; Draxler et al. 2015) and fungal spores (Meyer et al. 2017a, b; Olivera et al. 2015). An LPDM is used here as it allows a robust representation of complex threedimensional turbulent transport over very long distances between South Africa and Australia. It is widely accepted that LPDMs generally outperform simpler approaches such as mean trajectory models (Lin 2013; Stohl et al. 2002). The key idea of a LPDM is to use the statistical properties of the wind velocity field to determine stochastic displacements of simulation particles in such a way that the entire particle-ensemble follows the three-dimensional probability distribution of the position (and velocity) of real-life particulates (e.g., spores) in the atmospheric flow field (Lin 2013). Each simulation particle moves according to a Langevin type stochastic differential equation, which is usually defined by assuming Markovian properties of the noise term, with additional technical specifications that include determining the coefficients of displacement from the input meteorology and empirical fits to turbulence profiles (Jones 2013; Lin 2013; Thomson 1987). From this probabilistic description of the position (and velocities) of particulates, one can then obtain concentrations in the air and further compute deposition fluxes as a function of meteorology and topography.

It is known that the transport of spore clouds is influenced by wind eddies of varying size (Gregory 1945). The complex LPDM simulation framework accounts for the influence of such turbulent air-motions on spore transport on different scales. For example, the following typical scenario of spore release and long-distance transport is accounted for in simulations: the topography surrounding wheat fields in source areas causes mechanically induced turbulence characterized by variations in wind speed and direction with occasional strong wind gusts that can lift a spore cloud above the canopy and away from the source area, while small-scale turbulence causes a diffusive expansion of the spore cloud. Daily heating of the entire region surrounding source-areas may cause thermal updrafts that lift the spore cloud to higher altitudes, where synoptic and continental scale circulation patterns such as anticyclones or strong prevailing winds like westerlies and jet streams then carry spores over very long distances.

The use of a LPDM with a high number of simulation particles and finely resolved three-dimensional meteorological input data extending over 14 years, allowed robust estimates of long-term mean probabilities of LDD. The complex transport patterns emphasized the necessity for complex simulation frameworks, as used in this study. Simpler models, such as mean trajectory models relying on a small number of constant pressure level trajectories, would not have been able to account for vertical transport, windshear, turbulence, spore viability, and spore deposition mechanisms. Because the quality of the meteorological data for the years 1968 to 1969 when races 194 and 326 were first detected in Australia was poor, it was decided to simulate long-term dispersal trends using recent, finely resolved global meteorological data as input. This was important because LDD are rare, stochastic events that strongly depend on the input meteorology. The assessment of long-term dispersal climatology conducted in this study provided a general assessment of the potential of dispersal between the two continents by providing mean frequencies of meteorological conditions that allow viable spore transport from southern Africa to Australia.

The LDD frequencies (Table 3) derived from the simulations represent long-term mean probabilities. As these depend on meteorological conditions, it was not possible to directly extrapolate the long-term trends for 2003 to 2016 to other time periods. However, given the long study period of 14 years, the mean transmission frequencies reflect likely outcomes over a large range of meteorological conditions for this geographic area, thus serving as strong indicative support for the possibility of urediniospore dispersal in other years.

Due to the large $(8,000$ to $12,000 \mathrm{~km})$ spatial distances involved, the number of simulation particles can be very low in the outer tails of deposition plumes that reach Australia. This represents a limitation of the statistical representation of spore concentrations and deposition fluxes in the outer spore cloud tails. The analysis was therefore restricted to distinguish days with any nonzero urediniospore deposition on wheat areas. Deposition amounts were plotted to analyze daily variations, but were not analyzed further because of the above mentioned inherent uncertainties in exact deposition amounts at low simulation-particle densities in the outer tails of plumes and also because of the absence of data on exact canopy escape rates at the different sources.

While a conservative 3-day maximum lifetime for stem rust urediniospores (Maddison and Manners 1972) was first used in simulations, a small increase to 5 days strongly increased the number of times spore clouds reached Australia (Supplementary Movies S1, S2, and S3). This sensitivity of LDD frequencies to maximum spore lifetime emphasized the need to accurately determine the survival time distribution of spores in large samples in relation to UV radiation, temperature and humidity. While it is known that low temperatures at high transport altitudes decrease spore viability especially if spores have a high water content (Roelfs et al. 1992), temperatures below freezing are not lethal to $P$. graminis f. sp. tritici urediniospores, but induce a heatreversible dormancy after which a proportion of urediniospores can still successfully germinate (Bushnell and Roelfs 1985). The exact proportion of spores in a large sample that survives different UV radiation, temperature and air humidity regimes is however unknown, because current experimental results are based on very small sample sizes of a few hundred spores. This leads to uncertainties around the proportion of deposited spores that remain viable.

For the source location in central South Africa, there was a small number of days in all tested years on which some simulation particles reached Australian wheat areas. This indicated that meteorological conditions allowed urediniospore movement on extremely rare (single events in decades) to rare (single events per year) occasions. It is however important to distinguish between the frequency of days on which meteorological conditions would allow spore dispersal and the expected frequency of days with successful transmission which depends on the frequency of outbreaks and number of released spores per outbreak at the source.

With three confirmed southern African $P$. graminis f. sp. tritici incursions into Australia in 44 years (Burdon et al. 1982; Watson 
and de Sousa 1982), a simple "back-of-the-envelope" calculation demonstrates that transmission frequencies obtained with the current simulations are within a plausible range when compared with the actual values. The frequency of observed transmissions $\left(F_{\text {obs }}\right)$ can be calculated as $F_{\text {obs }}=3$ incursions $/ 44$ years $=0.068$ incursions per year. The expected mean transmission frequency $\left(F_{\text {est }}\right)$ can simply be calculated as the product of the simulated longterm mean proportion of release days with viable transmission to Australia, $\bar{P}$, and the approximate frequency of spore release days per year $\left(F_{\text {rel }}\right.$ per year). So, if we assume that on average there is 1 day per year with high spore canopy escape rates at the central South African source (or one outbreak with 10 days of release of high numbers of spores every 10 years), we obtain an estimated long-term expected transmission frequency $\left(F_{\text {est }}=\bar{P} \cdot F_{\text {rel }}\right)$ of 0.075 that is comparable to the observed value of 0.068 . However, the use of the long-term mean frequency as a constant proxy for the probability of transmission at any arbitrary day neglects the large variations (daily, monthly, and along years) in spore transmission probabilities. Exact daily canopy escape rates for spores must be known to accurately determine the number of days that high release at the source coincides with high transmission probabilities. As these data are not available, we restricted the release days to times of overlapping wheat seasons at the source and target and focused on long-term means derived from constant source-strength.

Large-scale stem rust outbreaks in South Africa are currently effectively controlled with genetic resistance and fungicides. This restricts the frequency and size of outbreaks which in turn reduces the probability, but does not exclude the possibility of future airborne dispersals to Australia. We showed that viable spore transport and deposition on wheat areas in Australia is possible and provided long-term mean frequencies of meteorological conditions that allow spore transport. Should a future stem rust outbreak occur in southern Africa, field data on urediniospore canopy escape rates (or approximate infected area, severity, incidence) could be used in the current dispersal model to approximate the number of urediniospores transported in real-time, allowing informed surveillance and control in Australia.

The relatively small differences in source-location coordinates made a notable difference in terms of long-term frequencies of viable urediniospore transmission events. This is intuitive considering synoptic atmospheric circulation systems. Urediniospore transport from source-locations in the northern parts of southern Africa is predominantly influenced by South-Easterly trade-winds with urediniospore-dispersal being restricted to Africa, reaching as far south as South Africa. In contrast, both source-locations in South Africa had dispersal patterns that would allow for urediniospore deposition in Australia because these urediniospores can be transported by winds associated with midlatitude westerlies, the Mascerene High, or in jet-streams toward Australia.

Even in the absence of direct $P$. graminis f. sp. tritici dispersal from Tanzania to Australia, rust inoculum from mid-Africa could eventually still reach Australia. The introduction of Ug99 races TTKSF and PTKST into South Africa was proposed to have occurred via the possible step-wise dispersal from mid-Africa through Zambia and Zimbabwe (Visser et al. 2011). This movement is supported by previous dispersal simulations identifying the key airborne migration routes between southern and eastern Africa (Meyer et al. 2017b), as well as by the LPMD simulations from the source in Tanzania in this study. The introduction of members of the Ug99 race group or any other African races into Australia is therefore possible, emphasizing the continued importance of field surveys in both countries.

While this study supported the incursions of races 21,326 , and 194 into Australia during the last 50 to 60 years, a similar case can be made for race 34 (and probably race 222 ), because both were detected in South Africa, Zimbabwe, and Mozambique between 1922 and 1970 (Pretorius et al. 2007). It was thought that race 34 in Australia developed from somatic hybridization between races 126 and 21 that gave rise to 34-2,11. A recent study however also suggested the sequential clonal development of race 34 variants from race 21-0 (Zhang et al. 2017). In addition, variants of standard race 222 were present at the same time as race 126 (Luig and Watson 1970), while 222-1,2,3,5,6 was collected in 1974 in South Australia (Watson and de Sousa 1982). The latter is thought to have arisen in Australia through mutation from 326 and 194.

The genetic similarity between the South African races and Australian race 34 variants, as well as 222-1,2,3,5,6+Einkorn, alternatively implies that both could represent additional incursions into Australia from southern Africa, thereby increasing the number of known incursions to five. Failure to detect these races as incursions might have been due to the fact that their phenotypes did not differ much from the races already present, as was the case for 126 and 222 (Luig and Watson 1970).

In conclusion, both the genetic and simulation studies supported the historical movement of $P$. graminis $\mathrm{f}$. $\mathrm{sp}$. tritici by wind from Africa to Australia, while also suggesting that more undetected incursions could have occurred. This raises two interesting questions. Were other disease-causing microbes similarly transported from Africa to Australia? And, because this extreme LDD event can happen, could similar transmissions have occurred between Australia and South America, and between South America and southern Africa? The evidence presented strongly suggests that rare windborne incursions of African $P$. graminis f. sp. tritici urediniospores can pose a threat to wheat production in Australia.

\section{ACKNOWLEDGMENTS}

We thank H. Karaoglu (genetic analysis) and M. Calleja (computing) for technical assistance. Logistical support from the Met Office, UK, is gratefully acknowledged.

\section{LITERATURE CITED}

Arnaud-Haond, S., and Belkhir, K. 2007. GenClone: A computer program to analyze genetic data, test for clonality and describe spatial clonal organization. Mol. Ecol. Notes 7:15-17.

Aylor, D. E. 2003. Spread of plant disease on a continental scale: Role of aerial dispersal of pathogens. Ecology 84:1989-1997.

Aylor, D. E., Schmale, D. G., Shields, E. J., Newcomb, M., and Nappo, C. J. 2011. Tracking the potato late blight pathogen in the atmosphere using unmanned aerial vehicles and Lagrangian modeling. Agric. For. Meteorol. 151:251-260.

Bowden, J., Gregory, P. H., and Johnson, C. G. 1971. Possible wind transport of coffee leaf rut across the Atlantic Ocean. Nature 229:500-501.

Brown, K. M., and Hovmøller, M. S. 2002. Aerial dispersal of pathogens on the global and continental scales and its impact on plant disease. Science 297:537-541.

Burdon, J. J., Marshall, D. R., Luig, N. H., and Gow, D. J. S. 1982. Isozyme studies on the origin and evolution of Puccinia graminis f. sp. tritici in Australia. Aust. J. Biol. Sci. 35:231-238.

Burgin, L., Gloster, J., Sanders, C., Mellor, P. S., Gubbins, S., and Carpenter, S. 2013. Investigating incursions of bluetongue virus using a model of longdistance Culicoides biting midge dispersal. Transbound. Emerg. Dis. 60: 263-272.

Bushnell, W. R., and Roelfs, A. P. (eds.) 1985. The Cereal Rusts, Vol. I. Origins, Specificity, Structure, and Physiology. Academic Press, Orlando, FL.

Carnegie, A., Lidbetter, J., Walker, J., Horwood, M., Tesoriero, L., Glen, M., and Priest, M. 2010. Uredo rangelii, a taxon in the guava rust complex, newly recorded on Myrtaceae in Australia. Australas. Plant Pathol. 39: 463-466.

Chen, W. Q., Wu, L. R., Liu, T. G., Xu, S. C., Jin, S. L., Peng, Y. L., and Wang, B. T. 2009. Race dynamics, diversity and virulence evolution in Puccinia striiformis $\mathrm{f}$. sp. tritici, the causal agent of wheat stripe rust in China from 2003 to 2007. Plant Dis. 93:1093-1101.

Davies, T., Cullen, M. J. P., Malcolm, A. J., Mawson, M. H., Staniforth, A., White, A. A., and Wood, N. 2005. A new dynamical core for the Met Office's global and regional modelling of the atmosphere. Q. J. R. Meteorol. Soc. 131:1759-1782.

Draxler, R., Arnold, D., China, M., Galmarini, S., Hort, M., Jones, A., Leadbetter, S., Malo, A., Maurer, C., Rolph, G., Saito, K., Servranckx, R., Shimbori, T., Solazzo, E., and Wotawa, G. 2015. World Meteorological 
Organization's model simulations of the radionuclide dispersion and deposition from the Fukushima Daiichi nuclear power plant accident. J. Environ. Radioact. 139:172-184.

Evanno, G., Regnaut, S., and Goudet, J. 2005. Detecting the number of clusters of individuals using the software STRUCTURE: A simulation study. Mol. Ecol. 14:2611-2620.

Eversmeyer, M. G., and Kramer, C. L. 2000. Epidemiology of wheat leaf and stem rust in the central great plains of the USA. Annu. Rev. Phytopathol. 38:491-513.

Excoffier, L., Laval, G., and Schneider, S. 2005. Arlequin ver. 3.0: An integrated software package for population genetics data analysis. Evol. Bioinform. Online 1:47-50.

Excoffier, L., Smouse, P. E., and Quattro, J. M. 1992. Analysis of molecular variance inferred from metric distances among DNA haplotypes: Application to human mitochondrial DNA restriction data. Genetics 131:479-491.

Fonseca, N. 1972. Raças fisiológicas de Puccinia graminis Pers. f. sp. tritici (Eriks. \& E. Henn.) em Moçambique. I - Resultados da prospecção feita em 1970. Instituto de Investigação Agronomica de Moçambique, Informação Técnica no. 51.

Goudet, J. 2001. FSTAT, a program to estimate and test gene diversities and fixation indices. 2.9.3 ed

Granados, G. M., McTaggart, A. R., Barnes, I., Rodas, C. A., Roux, J., and Wingfield, M. J. 2017. The pandemic biotype of Austropuccinia psidii discovered in South America. Australas. Plant Pathol. 46:267-275.

Gregory, P. H. 1945. The dispersion of air-borne spores. Trans. Br. Mycol. Soc. 28:26-72.

Hartl, D. L., and Clark, A. G. 1997. Principles of Population Genetics, 3rd ed. Sinauer Associates, Sunderland, MA.

Isard, S. A., Gage, S. H., Comtois, P., and Russo, J. M. 2005. Principles of aerobiology applied for invasive species applied to soybean rust. Bioscience 55:851-862.

Jombart, T., Devillard, S., and Balloux, F. 2010. Discriminant analysis of principal components: A new method for the analysis of genetically structured populations. BMC Genet. 11:94.

Jones, A. R. 2013. User guide for NAME. UK Met Office, Exeter, UK.

Jones, A. R., Thomson, D. J., Hort, M. C., and Devenish, B. 2007. The U.K. Met Office's next-generation atmospheric dispersion model, NAME III. Pages 580-589 in: Air Pollution Modeling and Its Application XVII. C. Borrego and A.-L. Norman, eds. Springer.

Karaoglu, H., Lee, C. M. Y., and Park, R. 2013. Simple sequence repeats in Puccinia graminis: Abundance, cross-formae speciales and intra-species utility, and development of novel markers. Australas. Plant Pathol. 42: 271-281.

Kim, K. S., and Beresford, R. M. 2008. Use of a spectrum model and satellite cloud data in the simulation of wheat stripe rust (Puccinia striiformis) dispersal across the Tasman Sea in 1980. Agric. For. Meteorol. 148: 1374-1382.

Kolmer, J. A. 2001. Molecular polymorphism and virulence phenotypes of the wheat leaf rust fungus Puccinia triticina in Canada. Can. J. Bot. 79: 917-926.

Kopelman, N. M., Mayzel, J., Jakobsson, M., Rosenberg, N. A., and Mayrose, I. 2015. CLUMPAK: A program for identifying clustering modes and packaging population inferences across $K$. Mol. Ecol. Resour. 15: 1179-1191.

Lewis, C. M., Persoons, A., Bebber, D. P., Kigathi, R. N., Maintz, J., Findlay, K., Bueno-Sancho, V., Corredor-Moreno, P., Harrington, S. A., Kangara, N., Berlin, A., García, R., Germán, S. E., Hanzalová, A., Hodson, D. P., Hovmøller, M. S., Huerta-Espino, J., Imtiaz, M., Iqbal Mirza, J., Justesen, A. F., Niks, R. E., Omrani, A., Patpour, M., Pretorius, Z. A., Roohparvar, R., Sela, H., Singh, R. P., Steffenson, B., Visser, B., Fenwick, P. M., Thomas, J., Wulff, B. H., and Saunders, D. G. O. 2018. Potential for re-emergence of wheat stem rust in the United Kingdom. Commun. Biol. 1:13.

Lin, J. C. 2013. Lagrangian modelling of the atmosphere: An introduction. Pages 1-11 in: Geophysical Monograph Series. J. Lin, D. Brunner, C. Gerbig, A. Stohl, A. Luhar, and P. Webley, eds. American Geophysical Union.

Luig, N. H. 1977. The establishment and success of exotic strains of Puccinia graminis f. sp. tritici in Australia. Proc. Ecol. Soc. Aust. 10:89-96.

Luig, N. H., and Watson, I. A. 1970. The effect of complex resistance in wheat on the variability of Puccinia graminis f. sp. tritici. Proc. Linn. Soc. N. S. W. 95:22-45.

Maddison, A. C., and Manners, J. G. 1972. Sunlight and viability of cereal rust uredospores. Trans. Br. Mycol. Soc. 59:429-443.

Meyer, M., Burgin, L., Hort, M. C., Hodson, D. P., and Gilligan, C. A. 2017a. Large-scale atmospheric dispersal simulations identify likely airborne incursion routes of wheat stem rust into Ethiopia. Phytopathology 107: 1175-1186.

Meyer, M., Cox, J. A., Hitchings, M. D. T., Burgin, L., Hort, M. C., Hodson, D. P., and Gilligan, C. A. 2017b. Quantifying airborne dispersal routes of pathogens over continents to safeguard global wheat supply. Nat. Plants 3: $780-786$

Nagarajan, S., and Singh, D. V. 1990. Long distance dispersion of rust pathogens. Annu. Rev. Phytopathol. 28:139-153.

Nagarajan, S., Singh, H., Joshi, L. M., and Saari, E. E. 1976. Meteorological conditions associated with long-distance dissemination and deposition of Puccinia graminis tritici uredospores in India. Phytopathology 66:198-203.

Olivera, P., Newcomb, M., Szabo, L. J., Rouse, M., Johnson, J., Gale, S., Luster, D. G., Hodson, D., Cox, J. A., Burgin, L., Hort, M., Gilligan, C. A., Patpour, M., Justesen, A. F., Hovmøller, M. S., Woldeab, G., Hailu, E., Hundie, B., Tadesse, K., Pumphrey, M., Singh, R. P., and Jin, Y. 2015. Phenotypic and genotypic characterization of race TKTTF of Puccinia graminis $\mathrm{f}$. sp. tritici that caused a wheat stem rust epidemic in southern Ethiopia in 2013-14. Phytopathology 105:917-928.

Orr, G. F., and Trippets, W. C. 1972. Morphology and other physical characteristics of urediospores possibly related to aerodynamics and long range travel. Mycopathol. Mycol. Appl. 48:143-159.

Pan, Z., Yang, X. B., Pivonia, S., Xue, L., Pasken, R., and Roads, J. 2006. Long-term prediction of soybean rust entry into the continental United States. Plant Dis. 90:840-846.

Park, R. F. 2007. Stem rust of wheat in Australia. Aust. J. Agric. Res. 58: 558-566.

Park, R. F., Burdon, J. J., and McIntosh, R. A. 1995. Studies on the origin, spread, and evolution of an important group of Puccinia recondita $\mathrm{f}$. sp. tritici pathotypes in Australasia. Eur. J. Plant Pathol. 101:613-622.

Park, R. F., Fetch, T., Hodson, D., Jin, Y., Nazari, K., Prashar, M., and Pretorius, Z. A. 2011. International surveillance of wheat rust pathogens-Progress and challenges. Euphytica 179:109-117.

Park, R. F., Jahoor, A., and Felsenstein, F. G. 2000. Population structure of Puccinia recondita in Western Europe during 1995, as assessed by variability in pathogenicity and molecular markers. J. Phytopathol. 148: 169-179.

Perrier, X., Flori, A., and Bonnot, F. 2003. Data analysis methods. Pages 31-63 in: Genetic Diversity of Cultivated Tropical Plants. P. Hamon, M. Seguin, X. Perrier, and J. C. Glazmann, eds. Science Publishers, Icn and Cirad, Montpellier.

Pretorius, Z. A., Pakendorf, K. W., Marais, G. F., Prins, R., and Komen, J. S. 2007. Challenges for sustainable cereal rust control in South Africa. Aust. J. Agric. Res. 58:593-601.

Pretorius, Z. A., Singh, R. P., Wagoire, W. W., and Payne, T. S. 2000. Detection of virulence to wheat stem rust resistance gene Sr31 in Puccinia graminis f. sp. tritici in Uganda. Plant Dis. 84:203.

Pritchard, J. K., Stephens, M., and Donnelly, P. 2000. Inference of population structure using multilocus genotype data. Genetics 155:945-959.

Prussin, A. J., Marr, L. C., Schmale, D. G., Stoll, R., and Ross, S. D. 2015. Experimental validation of a long-distance transport model for plant pathogens: Application to Fusarium graminearum. Agric. For. Meteorol. 203:118-130.

Purdy, L. H., Krupa, S. V., and Dean, J. L. 1985. Introduction of sugarcane rust into the Americas and its spread to Florida. Plant Dis. 69:689-693.

Roelfs, A. P., Singh, R. P., and Saari, E. E. 1992. Rust Diseases of Wheat: Concepts and Methods of Disease Management. CIMMYT, Mexico.

Rotem, J., Wooding, B., and Aylor, D. E. 1985. The role of solar radiation, especially ultraviolet, in the mortality of fungal spores. Phytopathology 75 : 510-514.

Sadyś, M., Skjøth, C. A., and Kennedy, R. 2014. Back-trajectories show export of airborne fungal spores (Ganoderma sp.) from forests to agricultural and urban areas in England. Atmos. Environ. 84:88-99.

Sambrook, J., Fritsch, E. F., and Maniatis, T. 1989. Pages 6.3-6.46 in: Molecular Cloning: A Laboratory Manual, 2nd ed. Cold Spring Harbor Laboratory, New York.

Schmale, D. G., and Ross, S. D. 2015. Highways in the sky: Scales of atmospheric transport of plant pathogens. Annu. Rev. Phytopathol. 53: 591-611.

Schneider, R. W., Hollier, C. A., Whitam, H. K., Palm, M. E., McKemy, J. M., Hernández, J. R., Levy, L., and DeVries-Paterson, R. 2005. First report of soybean rust caused by Phakopsora pachyrhizi in the continental United States. Plant Dis. 89:774.

Singh, R. P., Hodson, D. P., Huerta-Espino, J., Jin, Y., Bhavani, S., Njau, P., Herrera-Foessel, S., Singh, P. K., Singh, S., and Govindan, V. 2011. The emergence of $\mathrm{Ug} 99$ races of the stem rust fungus is a threat to world wheat production. Annu. Rev. Phytopathol. 49:465-481.

Singh, R. P., Hodson, D. P., Jin, Y., Huerta-Espino, J., Kinyua, M. G., Wanyera, R., Njau, P., and Ward, R. W. 2006. Current status, likely migration and strategies to mitigate the threat to wheat production from race $\mathrm{Ug} 99$ (TTKS) of stem rust pathogen. CAB Rev. Perspect. Agric. Vet. Sci. Nutr. Nat. Resour. 54:1-13

Singh, R. P., Hodson, D. P., Jin, Y., Lagudah, E. S., Ayliffe, M. A., Bhavani, S., Rouse, M. N., Pretorius, Z. A., Szabo, L. J., Huerta-Espino, J., Basnet, 
B. R., Lan, C., and Hovmøller, M. S. 2015. Emergence and spread of new races of wheat stem rust fungus: Continued threat to food security and prospects of genetic control. Phytopathology 105:872-884.

Stenberg, P., Lundmark, M., and Saura, A. 2003. MLGsim: A program for detecting clones using a simulation approach. Mol. Ecol. Notes 3:329-331.

Stohl, A., Eckhardt, S., Forster, C., James, P., Spichtinger, N., and Seibert, P. 2002. A replacement for simple back trajectory calculations in the interpretation of atmospheric trace substance measurements. Atmos. Environ. 36:4635-4648.

Thomson, D. J. 1987. Criteria for the selection of stochastic models of particle trajectories in turbulent flows. J. Fluid Mech. 180:529-556.

Tomar, S. M. S., Singh, S. K., Sivasamy, M., and Vinod. 2014. Wheat rusts in India: Resistance breeding and gene deployment-A review. Indian J. Genet. 74:129-156.

Viljanen-Rollinson, S. L. H., and Cromey, M. G. 2002. Pathways of entry and spread of rust pathogens: Implications for New Zealand's biosecurity. N. Z. Plant Prot. 55:42-48.

Visser, B., Herselman, L., Park, R. F., Karaoglu, H., Bender, C. M., and Pretorius, Z. A. 2011. Characterization of two new Puccinia graminis f. sp. tritici races within the Ug99 lineage in South Africa. Euphytica 179: 119-127.

Wang, H., Yang, X. B., and Ma, Z. 2010. Long-distance spore transport of wheat stripe rust pathogen from Sichuan, Yunnan and Guizhou in Southwestern China. Plant Dis. 94:873-880.
Watson, I. A. 1958. The present status of breeding disease resistant wheats in Australia. Agric. Gaz. N.S.W. 69:630-660.

Watson, I. A., and de Sousa, C. N. A. 1982. Long distance transport of spores of Puccinia graminis tritici in the southern hemisphere. Proc. Linn. Soc. N. S. W. 106:311-321.

Weil, T., De Filippo, C., Albanese, D., Donati, C., Pindo, M., Pavarini, L., Carotenuto, F., Pasqui, M., Poto, L., Gabrieli, J., Barbante, C., Sattler, B., Cavalieri, D., and Miglietta, F. 2017. Legal immigrants: Invasion of alien microbial communities during winter occurring desert dust storms. Microbiome 5:32-42.

Wellings, C. R., McIntosh, R. A., and Walker, J. 1987. Puccinia striiformis f. sp. tritici in Eastern Australia-Possible means of entry and implications for plant quarantine. Plant Pathol. 36:239-241.

Wilkinson, A. G., and Spiers, A. G. 1976. Introduction of the poplar rusts Melampsora larici-populina and M. medusae to New Zealand and their subsequent distribution. N. Z. J. Sci. Dunedin. 19:195-198.

You, L., Wood-Sichra, U., Fritz, S., and See, L. 2005. Spatial Production Allocation Model (SPAM) 2005. v2.0. http://mapspam.info/

Zhang, J., Zhang, P., Karaoglu, H., and Park, R. 2017. Molecular characterisation of Australian isolates of Puccinia graminis f. sp. tritici supports long-term clonality but also reveals cryptic genetic variation. Phytopathology 107:1032-1038.

Zwer, P. Z., Park, R. F., and McIntosh, R. A. 1992. Wheat stem rust in Australia 1969-1985. Aust. J. Agric. Res. 43:399-431. 